\title{
Authors' reply to the comment by Petros et al. on "Retropubic versus transobturator MUS: Time to revisit?" by Lose and Klarskov
}

\author{
Gunnar Lose $^{1}$ • Niels Klarskov ${ }^{1}$ (D) - Werner Schaefer ${ }^{1}$
}

Received: 15 September 2017 / Accepted: 9 October 2017 /Published online: 6 November 2017

(C) The International Urogynecological Association 2017

We thank Peter Petros for his comments, although it is somewhat difficult to follow his argumentation for the anatomical basis for the higher failure rate after transobturator mid urethral slings (T-MUS). We do not think that Poiseuille's law can be used to explain incontinence, as the assumptions is not fulfilled; the law is true for steady flow in a rigid pipe. However, the urethra is definitely not a rigid pipe, and there is no steady flow during stress episodes.

No clinical or urodynamic data indicate that retropubic MUS (R-MUS) and T-MUS have different mechanism of action; however, biomechanically, R-MUS provide stronger support than T-MUS, which can be illustrated with the following simple figure based on sound physical principles, which imply that all forces are in full balance (equilibrium) (Fig. 1).

Niels Klarskov,

Gunnar Lose,

Werner Schaefer

This reply refers to the comment available at https://doi.org/10.1007/ s00192-017-3485-2

Gunnar Lose

Gunnar.Lose@regionh.dk

Niels Klarskov

Niels.Klarskov@regionh.dk

Werner Schaefer

Werner.Schaefer@pitt.ed

1 Department of Obstetrics and Gynecology, Herlev Hospital, Herlev Ring, Herlev, Denmark a

b

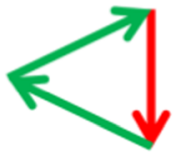

1

C
R-MUS

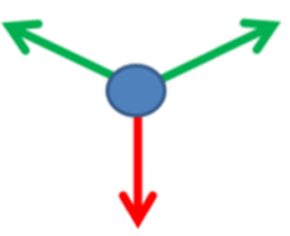

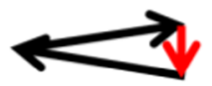

T-MUS

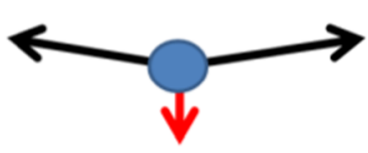

Fig. 1 A force is a vector which has a magnitude and a direction. The force can therefore perfectly be presented by an arrow where the magnitude is proportional to the length of the arrow and the direction is shown by the arrow. If a weight is hanging in a structure (e.g., ligament), then the magnitude of the weight is equal to the force in the ligament and the direction is opposite (a). The weight that can be balanced by the ligaments depends on the angle between the ligaments and the weight, which can be easily illustrated, as the arrows must add up in a triangular combination for the force to be in balance (b). Hence, it is clear that the more horizontal the support, the less weight the ligaments (MUS) can suspend. Thus, as the T-MUS is placed more horizontally, it provides less support compared with the R-MUS (c) and is a plausible explanation for the higher reoperation rate after the T-MUS 